\title{
Experiência do desmame entre mulheres de uma mesma família
}

\author{
WEANING EXPERIENCES AMONG WOMEN FROM THE SAME FAMILY \\ EXPERIÉNCIA DEL DESTETE ENTRE MUJERES DE UNA MISMA FAMILIA
}

\author{
Joseila Sonego ${ }^{1}$, Isabel Cristina Pacheco Van der Sand ${ }^{2}$, Ana Maria de Almeida ${ }^{3}$, \\ Flávia Azevedo Gomes ${ }^{4}$
}

\section{RESUMO}

Trata-se de um estudo de caso que objetivou conhecer os motivos que levaram mulheres-mães, de uma mesma familia, a realizarem o desmame de seus filhos e identificar os sentimentos que acompanham essas mulheres durante esse processo. Para a coleta dos dados, utilizou-se a entrevista semi-estruturada e, para a análise, as orientações metodológicas de Minayo (1993). Concluiu-se que o desmame acontece em razão de uma nova gestação, idade da criança, doença da mãe ou do filho e recusa do peito pela criança. Verificou-se que o desmame pode ser tranqüilo para algumas mulheres, enquanto para outras é acompanhado de sofrimento. Por meio das falas das mulheres-mães estudadas, observamos que o discurso dos formuladores de politica sobre o aleitamento materno parece influenciar bastante na construção dessa prática, atuando mais que as de gerações anteriores da família.

\section{PALAVRAS-CHAVE}

Aleitamento materno.

Desmame.

Saúde da mulher.

\author{
ABSTRACT \\ This work is a case study that \\ aimed to acknowledge the \\ reasons that persuade women- \\ mothers from a same family to \\ wean their children, and \\ identify the feelings that \\ accompany these women \\ during this process. A semi- \\ structured interview was used \\ for data collection, and the \\ analysis was done using \\ Minayo's (1993) \\ methodological orientations. It \\ was concluded that weaning \\ takes place due to various \\ reasons such as: a new \\ pregnancy, child's age, \\ mother's or child's disease, \\ and breast refusal by the child. \\ It was verified that weaning \\ can be soothing for some \\ women while for others it is \\ accompanied by suffering. \\ Through the studied women- \\ mother's speeches, it was \\ observed that policymakers' \\ discourses on breast-feeding \\ seem to influence a lot on this \\ practice, having better results \\ on the youngest ones than the \\ previous generations of the \\ family.
}

\section{KEYWORDS}

Breastfeeding.

Weaning.

Woman's health.

\section{RESUMEN}

Éste estudio de caso tuvo como objetivos conocer las razones que han llevado a las mujeresmadres, de una misma familia, a destetar a sus hijos $y$ reconocer sus sentimientos durante ese proceso. Para la recolección de datos utilizamos la entrevista semi-estructurada y para el análisis de los mismos seguimos las orientaciones metodológicas de Minayo (1993). Fue concluido que el destete obedece a diferentes razones: un nuevo embarazo, edad del niño, enfermedad de la madre o del niño y rechazo del pecho por el niño. Fue verificado que el destete puede ser tranquilo para algunas mujeres, mientras que para otras está acompañado de sufrimiento. Por medio de los discursos de las mujeres madres estudiadas, observamos que el discurso de los formuladores de política sobre el amamantamiento materno parece influir bastante en la construcción de esa práctica, actuando más que las de generaciones anteriores de la familia.

\footnotetext{
1 Enfermeira e Mestranda pelo Programa de PósGraduação de Enfermagem em Saúde Pública da Escola de Enfermagem de Ribeirão Preto da Universidade de São Paulo (EERP/USP). joseilasonego@yahoo.com.br 2 Enfermeira e Mestre em Enfermagem Obstétrica. Docente da Universidade Regional do Noroeste do Estado do Rio Grande do Sul. isabel@unijui.tche.br

3 Enfermeira e Professora Doutora do Departamento de Enfermagem Materno-Infantil e Saúde Pública da EERP/USP. 4 Enfermeira e Professora Doutora do Departamento de Enfermagem Materno-Infantil e Saúde Pública da EERP/USP.
}

\section{PALABRAS CLAVE}

Lactancia materna.

Destete.

Salud de la mujer.

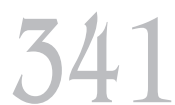

Rev Esc Enferm USP 2004; 38(1):341-9 


\section{INTRODUÇÃO}

$\mathrm{O}$ ato de amamentar reúne múltiplos aspectos, podendo ser entendido como um acontecimento pessoal e também social.

Quando a mãe escolhe a maneira de alimentar seu bebê, ela expressa, nessa decisão, influências da sociedade, do seu estilo de vida, da sua história pessoal e de sua personalidade ${ }^{(1)}$.

Nesse sentido, o estilo adotado pela mãe para atender às necessidades de seus filhos, aqui destacando a alimentação, é resultado de um processo de acumulação de informações e conhecimentos que são transmitidos de geração em geração por meio da herança cultural específica de cada grupo ${ }^{(2)}$. Dessa forma, o grupo social também terá influência nas atitudes adotadas pelas mulheres para conduzirem a alimentação de seus filhos.

O que une a dupla de amamentação é o afeto mútuo, em uma relação intensa, na qual mãe e filho precisam um do outro, tanto física quanto emocionalmente. Essa união, depois de estabelecida, torna-se difícil de ser desfeita, uma vez que sentimentos como o amor e a afetividade são estabelecidos nesse contato(3).

Há situações em que o aleitamento materno não é concretizado e por algumas razões as crianças são precocemente desmamadas em um período de suas vidas em que a amamentação natural exclusiva seria suficiente para garantir uma nutrição adequada.

As causas do desmame precoce foram estudadas em 71 grupos de incentivo ao aleitamento materno. A queixa mais freqüente estava relacionada à qualidade do leite materno _ "meu leite é fraco, não sustenta" _e essa situação era associada pelas mães a um intenso e freqüente choro do bebê. A partir desse dado, os autores buscaram identificar as causas do choro das crianças, quando perceberam que estavam relacionadas a problemas orgânicos e fisiológicos (cólicas). Apenas alguns bebês encontravam-se com dificuldades na amamentação, em virtude da sucção inadequada das mamas e sucção com aréola distendida, fato que poderia ser corrigido com orientações e apoio ${ }^{(4)}$.

Existem mulheres que, ao contrário do registrado acima, realizam desmame tardio em seus filhos, chegando a amamentar até os três anos da criança ou mais. Porém, independen- te da idade do filho, o desmame pode ser vivenciado de forma tranqüila por algumas mulheres e de maneira complicada por outras, constituindo-se em uma preocupação constante para a mãe que poderá ter dificuldades para concretizá-lo.

O processo do desmame pode ser influenciado por experiências maternas vividas durante a amamentação. No entanto, essa influência deve ser analisada a partir da compreensão do processo adaptativo da mulher à gestação, de sua história pessoal e familiar e principalmente das experiências anteriores relacionadas ao aleitamento materno ${ }^{(5)}$.

Mãe e filho é que precisariam decidir sobre o tempo que deve durar a amamentação, sendo que o momento de interrompê-la definitivamente é quando algum dos parceiros está definitivamente pronto para abandoná-la. O desmame é parte do processo de crescimento da criança e do amadurecimento da mãe ${ }^{(3)}$.

No que diz respeito à ocasião em que a amamentação deveria ser interrompida, é importante considerar que esta deve estar relacionada ao momento em que o seio materno pode ser substituído, pela criança, por outros objetos que tragam para ela o sentido de amor e suporte vivenciado no ato de amamentar. Para isso, é indicado o desmame progressivo, pois assim, enquanto o vínculo ao seio é desfeito, gradativamente, novos vínculos serão estabelecidos, como alimentos sólidos e brinquedos ${ }^{(6)}$.

Quanto ao significado psicológico do processo de desmame, é válido referirmos que:

(...) o momento de interrupção da amamentação concretizará diferentes posturas no relacionamento (da criança) com o mundo. Posturas estas que, embora iniciadas nestes momentos, tenderão a se expandir para todo o desenvolvimento futuro, ou seja, todas as modalidades de relações futuras poderão estar permeadas por este processo(6).

Têm sido relatadas práticas inadequadas que as mulheres utilizam no processo de desmame, quando o filho é desencorajado a desejar mamadas futuras. Na zona rural do México, por exemplo, as mães põem na mama pimenta do chili, uma substância amarga que quando experimentada pela criança, esta 
rejeita a mama. Já em certas regiões do Pacífico, as mamas são pintadas com tintas inofensivas, então os fillhos estranham a aparência modificada e negam o seio ${ }^{(3)}$. Outra técnica que é usada na Europa diz respeito ao fato de as mães afastarem-se dos bebês por quatro ou cinco dias, deixando-os com o pai ou parentes. Nesta prática, com a mãe ausente, espera-se que a criança abandone a amamentação $0^{(3)}$.

Na nossa realidade, essas mesmas estratégias têm sido adotadas para o desmame, sendo as mais comuns o uso de substâncias de sabor amargo ou apimentado e em algumas situações o distanciamento mãe e filho.

No que diz respeito à atuação dos enfermeiros no processo de desmame, estes precisariam estar disponíveis às famílias, prestando apoio para fortalecê-las no enfrentamento das atividades diárias relacionadas à saúde. Nesse contexto, podemos incluir a orientação quanto à alimentação complementar da criança, que contempla, também, o período do desmame.

Amamentar ou não um filho constitui-se, então, em uma tarefa que ultrapassa as barreiras do querer. A decisão materna de amamentar é um fato que poderá influenciar diretamente na concretização desse ato, porém a amamentação é um advento também social, muda conforme a época, os costumes e os valores e são transmitidos de geração para geração.

Nesse período, o apoio de profissionais da saúde à mulher-mãe é importante para que ela se sinta segura e sabendo que não está sozinha, podendo pedir ajuda quando achar necessário ${ }^{(7)}$.

Frente a essas considerações e compreendendo a amamentação como uma construção social e histórica, este trabalho tem como objetivos: conhecer os motivos que levaram mulheres-mães, que possuem entre si laços familiares, a realizarem o desmame de seus filhos e identificar os sentimentos que acompanham essas mulheres durante o processo de desmame.

\section{MATERIAL E MÉTODO}

O presente trabalho foi delineado como sendo do tipo estudo de caso, caracterizado como uma modalidade de pesquisa que cole- ta e registra informações de um ou de vários casos com o intuito de organizar um relato ordenado e crítico da situação investigada. Este tipo de estudo possibilita a tomada de decisões e a proposição de ação transformadora ${ }^{(8)}$.

Buscou-se configurar a experiência de sete mulheres-mães que passaram pelo processo de amamentação e desmame de seus filhos, independentemente do tempo em que amamentaram. As mulheres-mães possuem, entre si, laços familiares e compreendem três gerações de uma mesma família, sendo três delas da segunda geração, duas da terceira e duas da quarta.

Para manter o anonimato das colaboradoras do estudo, optamos por nomeá-las como deusas gregas: Hebe, Atena, Tétis, Héstia, Afrodite, Dafne e Artemisa.

Para a coleta dos dados da pesquisa realizamos entrevista semi-estruturada, tomando como roteiro as seguintes questões norteadoras: fale sobre os motivos que levaram a senhora a desmamar seus filhos e como foi desmamá-los?

As entrevistas foram gravadas em fita cassete após aquiescência das mulheresmães, que foram informadas dos objetivos da pesquisa. Elas assinaram o "Termo de Consentimento Livre e Esclarecido", após garantido o anonimato e o uso das informações apenas para fins científicos, conforme preconiza a Resolução 196/96 ${ }^{(9)}$ que estabelece as recomendações para pesquisas envolvendo seres humanos.

Para a análise das entrevistas, percorremos os seguintes passos: primeiro, a ordenação dos dados coletados através da transcrição das fitas cassetes e leitura do material; segundo, classificação dos dados com leitura exaustiva e repetida das entrevistas, compondo com o recorte das unidades de registro os temas mais relevantes e, terceiro, a análise final, levando em conta os objetivos da pesquisa e os temas que emergiram das entrevistas $^{(10)}$.

\section{RESULTADOS E DISCUSSÃO}

Do recorte das unidades de registro, emergiram duas categorias temáticas que estiveram presentes na história do desmame entre as mulheres pesquisadas, quais sejam:
Experiência do desmame entre mulheres de uma mesma família 
Joseila Sonego Isabel C. P. Van der Sand Ana Maria de Almeida Flávia Azevedo Gomes
- elementos motivadores para a prática do desmame e

- sentimentos presentes no processo do desmame.

\section{Elementos Motivadores para a Prática do Desmame}

Dentre os elementos motivadores para o desmame apontados pelas mulheres-mães, observamos que, diante de uma nova gravidez, pensando no bem-estar do filho que está para nascer, as colaboradoras optaram por interromper o aleitamento materno que estava em andamento, pois as pessoas de seu convívio social informavam que continuar amamentando durante a gestação resultaria em prejuízos à criança. As falas de HEBE e ATENA elucidam tal motivação:

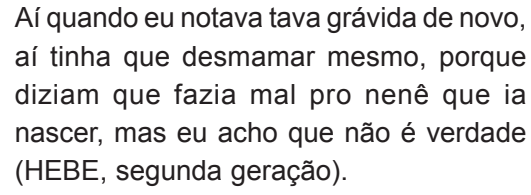

Eu, por exemplo, quando desmamei a TÉTIS, quando eu já precisava desmamar porque eu engravidei e diziam que fazia mal, que ficava fraco o nenê qu ia nascer (ATENA, segunda geração).

Os ensinamentos transmitidos por pessoas do círculo social parecem ser seguidos e respeitados pelas mulheres, porém uma questionou sobre sua veracidade, como nos contou HEBE na fala acima. Ela teve a oportunidade de realizar essa reflexão quando, por não saber da nova gravidez, continuou amamentando e percebeu que mesmo assim sua filha nasceu "bonita e gordinha", o que refere como características de uma criança saudável.

Em estudo realizado no interior do estado do Rio Grande do Sul, a ocorrência de uma nova gravidez também aparece como motivo para desmame. A autora destaca a herança cultural como fator que influencia nas decisões acerca do processo de alimentação do lactente, incluindo o desmame. Tal percepção pode ser apreendida nas falas de suas entrevistadas quando as mesmas relatavam que a opção pelo desmame, em conseqüência de nova gravidez, era recomendação de suas mães ou de pessoas mais idosas de sua rede social ${ }^{(11)}$.

O acúmulo de tarefas foi um outro motivo que levou as mulheres-mães deste estudo a desmamarem seus filhos, pois os vários afazeres do seu dia-a-dia ocasionavam cansaço físico evidenciado, em algumas vezes, pelo emagrecimento acentuado, o qual ao ser percebido pelos familiares, desencadeava uma pressão progressiva para que a criança fosse desmamada. HÉSTIA e AFRODITE: nos falam:

(...) mas é que da L. eu achava melhor (desmamar) porque eu tava magra e a gente se sentia até fraca, ela mamava bastante, e tinha que fazer todas as lidas de casa (HÉSTIA, segunda geração).

(...) quando eu tava trabalhando, eu tava muito magra daí a mãe começou a dizer que ele (a criança) tava com fome, que o leite não chegava, que era muito pouco, que não sei o que, e realmente eu já não tinha tanto leite quanto antes, daí ele começou a tomar leite normal (AFRODITE, quarta geração).

Dados semelhantes aos citados foram encontrados em um estudo que aborda a vivência de mulheres sobre o desmame (tardio) da criança. No mesmo, foi evidenciado que a opção por concretizar o desmame é influenciada pela preocupação da própria mãe e da família com sua saúde ${ }^{(6)}$.

Entre as mulheres estudadas, os conselhos apontados por outras mulheres da família como também por pessoas de convívio freqüente parecem influenciá-las, levando-as a optar pela concretização do desmame por acreditarem que o leite materno não estava tendo efeito nutritivo. Esse fato pode ser observado nas falas a seguir:

Porque diziam que o desenvolvimento da criança era pouco então tu tava com o leite fraco, então a gente ía detrás da vovó, da sogra, atrás da vizinha e vinha à comadre, elas diziam que tinha que dá outra coisa prá criança (ATENA, segunda geração).

(...) e depois sabe as comadres diziam 'hi! Já tá grande, tá na hora de parar' e tal, enchiam o saco, daí eu dava um jeito (HÉSTIA, segunda geração).

Outro motivo referido para o desmame que não condiz com a vontade materna foi a ocorrência de situações inesperadas, como doença da criança ou da própria mãe. Para ATENA, essa condição esteve presente na decisão do desmame de dois de seus cinco filhos: 
(...) ele mamou menos de 40 dias porque ele era doente, então ele não tinha força suficiente pra mamar, deu meningite nele (...) e daí ela tinha nove meses e me deu a hepatite e daí eu fui para o hospital e a L. [uma das filhas mais velhas] ficou com ela e o E. em casa, eu tava no hospital e eles iam na casa da nona (mãe dela) pra ela ajudar, foram eles que desmamaram a M., lá na mãe (ATENA, segunda geração).

A família, nessa situação, apareceu como suporte para auxiliar no cuidado dispensado às crianças, quando a mãe enfrenta problemas de saúde e precisa afastar-se do domicílio por determinado tempo.

Percebemos que existiram laços afetivos que possibilitaram a união dos membros familiares (netos/avôs) para juntos buscarem o bem-estar da criança, enquanto a mãe recebia cuidados médicos-hospitalares. Em variados momentos, os indivíduos assumem diferentes papéis no grupo familiar e efetivam relações intrafamiliares sob a forma de alianças e triângulos que se organizam por gerações, sexo, idade, distribuição de tarefas, entre outras ${ }^{(12)}$.

Algumas entrevistadas apontaram que desmamavam seus filhos quando estava "na hora" e este momento era identificado pela idade em que se encontrava a criança e/ou pelo fato de a mesma estar recebendo uma alimentação variada. HEBE, HÉSTIA e DAFNE falam de seus motivos para o desmame:

É, tinha que desmamar porque já tinha feito um aninho porque já começava a comer, depois se a gente saía prá cá e pra lá, eles ficavam em casa com as gurias, com o pai, assim (HEBE, segunda geração).

Quando elas comiam de tudo, e daí achava melhor ir desmamando (HÉSTIA, segunda geração).

(...) uma criança de dois/três anos mamando eu não acho tão legal, porque judia até da mãe, não tem porque tá mamando até essa idade, eu acho que até oito meses, dez ou até um ano tá bom, nessa idade eles já tão comendo papinha há tempo, os meus foram até oito meses (DAFNE, terceira geração).

Parece que, nos casos relatados, as mulheres-mães possuem uma crença sobre o tempo ideal para iniciar o desmame, tendo como idéia principal a de que não há necessidade de manter a amamentação a partir do momento em que a criança passa a ingerir alimentos sólidos, pois o leite materno já não é a fonte principal de nutrição.

Ao pensarmos no aleitamento materno como aporte de benefícios ao desenvolvimento físico da criança, essa concepção tem alicerce concreto. Porém, cabe destacar que a amamentação além de suprir as necessidades nutricionais do bebê, também influencia nos aspectos emocionais do mesmo. Assim, há situações em que a criança

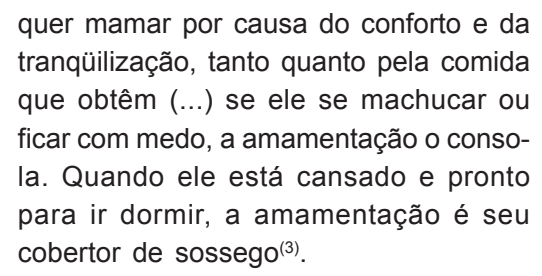

Assim, a criança poderá estar física e nutricionalmente preparada para interromper a amamentação, mas do ponto de vista psicoafetivo talvez ainda não seja o momento adequado para o abandono do aleitamento materno, pois a ocasião ideal para proceder à prática do desmame diz respeito ao momento em que a criança já possui outros objetos para satisfazê-la. Por essa razão há sugestões de um desmame progressivo, pois, à medida em que a criança desfaz o vínculo com o aleitamento materno, poderá estar adquirindo outros, que o substituirão ${ }^{(6)}$. Tal prática possivelmente fará com que o desmame seja vivenciado com o mínimo de traumas pelo binômio mãe/filho.

Em outras ocasiões, o aleitamento materno era interrompido em conseqüência de complicações mamárias apresentadas pela mulher, sendo que, sentindo importante desconforto durante a amamentação, optava por não oferecer mais a mama à criança. Tal atitude interrompia o estímulo de sucção e impedia a continuidade do aleitamento materno também pela falta da descida do leite. O referido motivo pode ser percebido nos depoimentos de ATENA e sua filha TÉTIS:

(...) porque quando inflamava o seio a gente criava figo e a gente não queria muito dá porque doía, né, então de repente o leite se ia, não tinha mais leite prá dá de mamar (ATENA, segunda geração).

Eu que resolvi parar porque não dava, nem pra mim não era bom, nem pro nenê (...) quando era hora do nenê mamar, eu pensava, aí Jesus, agora vem a hora do sacrifício (TÉTIS, terceira geração).
Experiência do desmame entre mulheres de uma mesma família 
Joseila Sonego Isabel C. P. Van der Sand Ana Maria de Almeida Flávia Azevedo Gomes

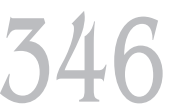

Rev Esc Enferm USP 2004; 38(1): 341-9.
TÉTIS apresentou mastite durante a amamentação de suas duas filhas e frente a esta situação decidiu por desmamá-las com um mês de vida. Percebemos que aleitar ao peito não proporcionava a ela sensações agradáveis, apenas dor, sofrimento e angústia. Ela refere ter muitas dúvidas em relação às origens desse problema, o que a fazia pensar que não possuía condições de amamentar suas filhas. Veja o que ela relatou:

(...) foi difícil, a AFRODITE com quinze dias tava minguadinha, ela chorava de fome (...) realmente eu acho que era eu que não tinha condições de amamentar, eu acho, se eu tivesse condições não dava isso e ainda todo mundo dizia: tenta, tenta, mas o seio cada vez maior, vermeIho, aquilo saía só infecção, não seria o certo, mas não deu certo, paciência... (TÉTIS, terceira geração).

Entre os motivos para o desmame precoce, as fissuras mamilares, o ingurgitamento mamário e, com menos freqüência, a mastite são apontados na literatura. Essas intercorrências contribuem na elaboração do significado da experiência de amamentar, o que interfere na decisão de continuar ou interromper a amamentação ${ }^{(13)}$.

Ao substituir o leite materno pelo leite artificial na alimentação das filhas, TÉTIS percebeu o resultado positivo que ele apresentou, fato que contribuiu para aumentar a idéia de que seu leite não alimentou as crianças do modo como esperava:

\section{(...) a AFRODITE olha, deu uma crescida e só foi isso aí (leite de vaca), se desenvol- veu através disso daí, porque o meu leite não deu, então é sinal que meu leite não serviu para nenhuma delas (TÉTIS, terceira geração).}

Pensamos que o aleitamento materno é benéfico quando mãe e filho sentem-se satisfeitos em realizá-lo, caso contrário, não formarão uma dupla de amamentação feliz e o afeto que poderia estar sendo compartilhado, possivelmente, será substituído pela dor e a agitação de ambas as partes. Portanto, essa situação exige auxílio da família e dos profissionais da saúde para que a mulher possa optar pela melhor conduta a ser adotada. Pode-se observar que TÉTIS se pauta na ilusão de que o leite de vaca é melhor quando sequer deu para AFRODITE a oportunidade de mamar.
A criança demonstrar aversão ao leite materno e recusar-se a mamar também foram motivos para a efetivação do desmame. ARTEMISA é quem fala sobre essa relação.

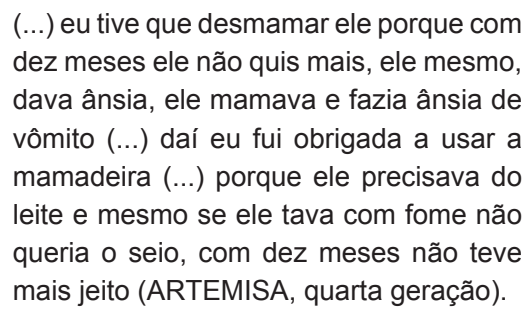

(...) eu tive que desmamar ele porque com dez meses ele não quis mais, ele mesmo, dava ânsia, ele mamava e fazia ânsia de vômito (...) daí eu fui obrigada a usar a mamadeira (...) porque ele precisava do leite e mesmo se ele tava com fome não queria o seio, com dez meses não teve mais jeito (ARTEMISA, quarta geração).

Nesse caso, mesmo a mãe não expressando desejo ou prontidão para o desmame, ela o adotou tendo como referência as necessidades nutricionais da criança. Essa não é uma situação incomum e

\section{(...) há ocasiões em que são as mães que se aferram ao confortável relacionamento de amamentação quando a própria crian- ça já está em condições de superá-lo ${ }^{(3)}$.}

A análise deste tema permitiu-nos perceber que são variados os motivos que levaram as mulheres-mães a optarem pelo desmame de seus filhos. Conhecer tais motivos nos forneceu subsídios para que possamos auxiliar/apoiar as mulheres, durante o ciclo gravídico-puerperal no enfrentamento de situações que possam vivenciar durante o processo de aleitamento materno.

\section{Sentimentos Presentes no Processo de Desmame}

O processo de desmame foi caracterizado pelas mulheres-mães como tranqüilo, quando aconteceu por decisão materna e sem causar traumas ao binômio mãe e filho. No decorrer das entrevistas, percebemos que as mulheres do estudo que passaram pelo desmame de seus filhos sem dificuldades foram aquelas que o caracterizaram como resultado do aleitamento materno bem-sucedido. Observe o que nos falam HEBE, DAFNE e AFRODITE:

(...) mas eu pra mim não achei que foi sacrifício pra desmamar porque quando eu achei que tava na hora fui tirando o seio aos poucos (HEBE, segunda geração).

Pra desmamar foi numa boa porque eu sabia que oito meses é suficiente, a criança já pode comer papinha e outras coisas (DAFNE, terceira geração). 
(...) eu achei que não teve problema pra desmamar, como eu disse, foi uma conseqüência, o meu leite diminuiu e ele foi parando aos poucos de mamar (AFRODITE, quarta geração).

As mulheres não encontraram dificuldades para o desmame, quando realizaram uma amamentação tranqüila, pois a base desse processo é a aquisição de uma boa experiência durante o aleitamento materno. Se a criança for amamentada com êxito, ela se sentirá feliz por ser desmamada, quando o momento chegar $^{(14)}$.

Nesse sentido, consideramos que ao perceber que o filho passa pelo processo de desmame com tranqüilidade e aceita a substituição total do leite materno por outros alimentos, possivelmente, a mulher-mãe terá seus medos e eventuais sentimentos de culpa diminuídos. Assim, esse período de separação do binômio poderá ser vivido sem traumas para mãe e filho, sendo provável que ambos guardem boas recordações desses momentos.

Nos depoimentos acima, HEBE nos conta que não "achou sacrifício" desmamar, porém, em outra ocasião referiu que em razão do desmame precisava fazer comida para as crianças, fato esse que, segundo ela, tornou o processo difícil. TÉTIS, por sua vez, comenta que a precária situação financeira em que se encontravam a fez sentir-se triste frente ao desmame, pois precisou desmamar precocemente suas filhas e por isso houve a necessidade de adquirir fontes alternativas de alimentos e seu alto custo interferia de modo negativo no orçamento familiar. Observe as falas a seguir:

Era difícil porque depois tinha que ficar fazendo a comida, porque primeiro tu dava qualquer coisinha e dava teta e tava alimentado, né? (HEBE, segunda geração).

Isso aí de eu não conseguir amamentar elas foi um sentimento muito grande, muita tristeza porque a gente gostaria de poder, porque no caso da F. a gente vivia assim, numa crise, que a gente não tinha da onde tirar prá comprar as coisas, no caso, eu te falei que vendi uma almofada porque não tinha dinheiro prá comprar o leite (TÉTIS, terceira geração).

Dentre os benefícios proporcionados pelo aleitamento materno, tais como nutrição de qualidade e proteção imunológica ao bebê, rápida involução uterina pós-parto e a forma- ção de vínculo entre o binômio mãe e fillho, é importante lembrarmos dos pontos positivos da amamentação para a situação financeira da família, pois, o leite materno não possui custos.

Sentimentos de tristeza também foram mencionados por ARTEMISA como presentes na ocasião em que precisou desmamar seu filho. O bebê, aos dez meses, começou a rejeitar o seio materno e, mesmo contrariada, ela optou por interromper o aleitamento materno. Observe o que ela nos diz:

\begin{abstract}
Ah! Eu queria continuar amamentando porque ele tava aumentando de peso, ele sempre foi saudável, eu vi que o meu leite dava resultado, eu fiquei triste quando ele não quis mais mamar, né, porque eu tinha tanto leite que ele poderia mamar até os três anos, se ele quisesse. Eu queria que ele tivesse continuado (...) até agora eu me pergunto por que ele não quis (ARTEMISA, quarta geração).
\end{abstract}

Na situação vivenciada por ARTEMISA, foi a criança, segundo ela, quem decidiu que chegara o momento de ser concretizado o desmame. A mãe que atribuiu o adequado crescimento e desenvolvimento do filho à eficácia de seu leite, sentiu-se triste e com muitas dúvidas frente a essa opção, sendo que até hoje se pergunta sobre o porquê de sua ocorrência.

Percebemos, na entrevista, que ela sentiuse rejeitada pelo filho não desejar mais ser amamentado. Ao mesmo tempo, a rejeição foi acompanhada por sentimento de culpa, que parece ter origem nos comentários das vizinhas que passaram a questioná-la sobre sua alimentação e uso de medicações, pois atribuí -ram a recusa do peito às atitudes maternas.

Assim, percebemos que as pessoas da rede social das mulheres-mães influenciam nos sentimentos que esse processo pode desencadear. A influência parece acontecer por meio de comentários, algumas vezes muito sutis, mas que para uma mãe fragilizada pela situação vivenciada, passam a ter importantes significados.

Embora num primeiro momento TÉTIS refira o sentimento de tristeza, é válido mencionarmos que o desmame para ela parece ter ocasionado sentimentos ambivalentes, pois além do processo desencadeado em razão de sua situação financeira, referiu que sentiu
Experiência do desmame entre mulheres de uma mesma família 
Joseila Sonego Isabel C. P. Van der Sand Ana Maria de Almeida Flávia Azevedo Gomes

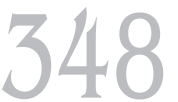

Rev Esc Enferm USP 2004; 38(1): 341-9.

"alívio" por ter desmamado suas filhas. Esse depoimento nos faz perceber que amamentar para ela tornou-se uma prática desagradável. Cabe lembrar que apresentou complicações mamárias como mastite, ambas as vezes que amamentou ao peito. Observe o que ela nos diz:

Prá mim foi um alívio o desmame; prá mim e prá elas também, porque elas se adaptaram bem com a alimentação que eu dei (leite em pó para a primeira filha e leite de vaca para a segunda), mas olha eu queria amamentar elas, toda mãe quer e eu tentei até que deu, mas por mais que eu queria não dava (...) (TÉTIS, terceira geração).

Parece-nos que TÉTIS precisa desculpar-se pelo fato de não ter amamentado suas filhas e faz isso dizendo que, apesar de ter concretizado o desmame, ela queria manter o aleitamento materno, porém não foi possível. TÉTIS traz consigo o discurso a respeito da mãe "ter que amamentar" seu filho, pois ela é responsável pela saúde do mesmo além do que, aleitar ao peito é a prova do amor materno, no imaginário coletivo. A gênese de tal concepção, possivelmente, está nas campanhas de incentivo ao aleitamento materno, e em conseqüência é transmitida pelos membros de sua rede social.

Como nos lembra Mota, citado por Silva ${ }^{(15)}$ :

\begin{abstract}
A ideologia, contida nas campanhas de incentivo ao aleitamento materno, proclama ser esta uma forma natural da mãe alimentar seu filho, considerada como resposta biológica e instintiva, motivada pelo amor materno. Coloca a mãe como responsável pela amamentação e pelas supostas conseqüências da sua ausência na saúde da criança, tanto física quanto emocional (...) de forma opressiva e violenta, mesmo que sutil e disfarçada.
\end{abstract}

Outro sentimento que, segundo as mulheres-mães esteve presente no processo de desmame foi a "pena" do filho que estava sendo desmamado. Acreditavam que se continuassem amamentando seria melhor para a criança, porém, caracterizavam o desmame como necessário e elas precisavam realizá-lo, mesmo desejando manter o aleitamento materno. HEBE, ATENA e HÉSTIA nos falam sobre esse sentimento:

Eu tinha pena deles porque se eles mamavam era melhor, mas a gente tinha que desmamar, né (HEBE, segunda geração).
O E. e a M. eu fiquei com pena deles porque eles eram tão pequenos, era melhor se tivessem mamado mais e eu tinha bastante leite não pude amamentar eles, um ficou doente e a outra eu tava no hospital, talvez eles tivessem mamado bastante igual a L. (ATENA, segunda geração).

Ah! Eu tinha peninha de desmamar, eu tinha bastante leite e pegar e tirar era uma judiaria, eu ficava preocupada porque ela mamava de noite e era mais difícil pra tirar de noite, mas precisava (HÉSTIA, segunda geração).

Por meio da análise desta categoria, reforçamos a necessidade de as mães receberem apoio dos profissionais de saúde no processo de desmame e, quando for oportuno, eles devem estar presentes para apoiar/ orientar as mulheres-mães que encontram dificuldades para concretizá-lo, pois, às vezes, desenvolvem sentimentos de culpa e dúvidas, que acabam não sendo bem elaborados sem ajuda profissional e, mesmo após ter passado anos, as mulheres permanecem se questionando sobre as causas do desmame.

\section{CONCLUSÕES}

As mulheres-mães que foram sujeitos neste estudo contaram suas histórias sobre a amamentação e desmame de seus filhos e falaram dos sentimentos envolvidos neste processo. Para algumas mulheres esta foi uma tarefa difícil, pois recordaram experiências que trouxeram sofrimento para elas e para as crianças.

A partir das histórias contadas, percebemos que para essas mulheres a amamentação e o desmame tiveram influência de fatores culturais como crenças, comportamentos, costumes e valores específicos do grupo. A influência familiar foi pouco visível, sendo mais marcante entre as mulheres-mães da segunda geração seguidas pelas da terceira geração.

A experiência particular de cada mulher mostrou-se determinante para a adoção de práticas relacionadas tanto à amamentação como ao desmame de seus filhos.

Como motivos apontados para a concretização, as mulheres-mães referiram a ocorrência de uma nova gestação; idade do filho como "tempo ideal" para o desmame; a ocorrência de doença na mãe ou na criança, bem como a recusa da criança ao leite materno. 
Com esta investigação, percebemos que o desmame pode acontecer de maneira tranqüila para algumas mulheres-mães, principalmente quando ele é uma decisão materna e o filho aceita, sem dificuldades, outro tipo de alimento. Porém, quando a interrupção do aleitamento materno não é tranqüila pode ser precursora de sentimentos como tristeza, compaixão da criança e alívio quando a amamentação traz prejuízos ao binômio mãe e filho. A decisão sobre manter a amamentação ou desmamar, portanto, parece ter sofrido pouca influência entre as gerações estudadas, prevalecendo a vontade da mãe ou da criança ou foi determinada por outras ocorrências adversas que contribuíram para essa decisão.

Através das falas das mulheres-mães estudadas, observamos que o discurso dos formuladores de política sobre o aleitamento materno parece influenciar na construção dessa prática, mais que as opiniões de gerações anteriores da família. Assim, o discurso das mulheres pauta-se na idade dos filhos, no retorno ao trabalho e na falta de suporte social para sua continuidade.

Ressaltamos, então, a importância de se valorizar o aleitamento materno na sua totalidade, incluindo o processo de desmame, pois as mulheres-mães apontam em suas falas que sentem-se responsáveis pelo sofrimento da criança, quando encontram dificuldades para realizá-lo e não recebem apoio adequado, podendo permanecer culpadas com relação ao desmame.

\section{REFERÊNCIAS}

(1) Maldonado MT. Psicologia da gravidez: parto e puerpério. $4^{\mathrm{a}}$ ed. Petrópolis: Vozes; 1981.

(2) Cabral IE, Tyrrel MAR. O estilo de cuidar da mãe e o trabalho da enfermagem. Rev Enferm. UERJ 1995; 3(2):189-95.

(3) Pdryor K. A arte de amamentar. Trad. de Maria Silva Mourão Netto. São Paulo: Summus; 1981.

(4) Siqueira R, Durso N, Almada AGP, Moreira MT, Massad GB. Reflexões sobre as causas do desmame precoce observadas em dinâmica de grupo de incentivo ao aleitamento materno. J Pediatr 1994; 70(1):16-20.

(5) Marcon SS. Vivências de mulheres sobre o desmame (tardio) da criança. Rev Gaúcha Enferm 1996; 17(1):43-50.

(6) Rapapport CR, Fiori WR, Herzberg E. Psicologia do desenvolvimento: a infância inicial: o bebê e sua mãe. São Paulo: EPU; 1981.

(7) Marcon SS, Elsen I. Criar os filhos: experiências de famílias de três gerações. Rev Bras Enferm 2000; 53(n ${ }^{\circ}$ esp):155-8.

(8) Chizzotti A. Pesquisa em ciências humanas e sociais. $3^{\mathrm{a}}$ ed. São Paulo: Cortez; 1998.
(9) Conselho Nacional de Saúde. Resolução n. 196 de 10 de outubro de 1996. Diretrizes e normas regulamentadoras de pesquisa envolvendo seres humanos. Brasília; 1997.

(10) Minayo MCS. O desafio do conhecimento: pesquisa qualitativa em saúde. $2^{\mathrm{a}}$ ed. São Paulo: Hucitec; 1993.

(11) Van der Sand ICP. O bem estar da criança sempre em primeiro lugar: o processo de alimentação do lactente sob a ótica de mulheres-mães de Ijuí/RS. [dissertação] São Paulo (SP): Escola de Enfermagem da USP; 1999.

(12) Fernandes AFC. O cotidiano da mulher com câncer de mama. Fortaleza: Fundação Cearense de Pesquisa e Cultura; 1997.

(13) Silva IA. Amamentar: uma questão de assumir riscos ou garantir benefícios. São Paulo: Robe ; 1997.

(14) Winnicot DW. A criança e seu mundo. Trad. de Álvaro Cabral. 6 a ed. Rio de Janeiro: Zahar; 1985. O desmame. p. 89-94.

(15) Silva IA. Reflexões sobre a prática do aleitamento materno. Rev Esc Enferm USP 1996; 30(1): 58-72.
Experiência do desmame entre mulheres de uma mesma família 